\title{
Consumer Perception of Antibiotic-Free and Hormone-Free Meat Products
}

\author{
Lindsey Newman
}

Dept. of Agriculture, Geosciences, and Natural Resources

256 Brehm Hall, Martin, TN 38237, United States

Tel: 1-731-881-7196_E-mail: rtewari@utm.edu

Joey Mehlhorn

Dept. of Agriculture, Geosciences, and Natural Resources

254 Brehm Hall, Martin, TN 38237, United States

Tel: 1-731-881-7275 E-mail: mehlhorn@utm.edu

Rachna Tewari (corresponding author)

Dept. of Agriculture, Geosciences, and Natural Resources

256 Brehm Hall, Martin, TN 38237, United States

Tel: 1-731-881-7196_E-mail: rtewari@utm.edu

Barbara Darroch

Dept. of Agriculture, Geosciences, and Natural Resources

103 Brehm Hall, Martin, TN 38237, United States

Tel: 1-731-881-7279_E-mail: bdarroch@utm.edu

Received: February 14, 2020 Accepted: September 3, 2020 Published: September 9, 2020 


\begin{abstract}
The use of food labels has become a popular resource that consumers use to determine if their food is safe. Some meat packages contain labels stating "antibiotic-free" or "hormone-free" meat, which can cause consumer concerns about health risk for other meat not labeled. The purpose of this study was to assess consumer views of meat that is labeled antibiotic-free or hormone-free, and meat that lacks those labels. A survey was created to determine consumer perception of meat products and sent to approximately 162 potential respondents. Ninety-one adults participated in the survey for a response rate of $56 \%$. Chi-square tests were used to determine if age, agriculture knowledge or education level was related to the participants' responses to selected survey questions. Agriculture knowledge was significant in consumer perception of non-labeled meat being healthier $(\mathrm{P}=0.0017)$, willingness to pay more for labeled products $(\mathrm{P}=0.0009)$ and concern for purchasing products not labeled $(\mathrm{P}=0.0362)$. Education level and age had no significant relationship to any questions asked in the survey. The perception that meat products lacking labels contain antibiotics or hormones is not related $(\mathrm{P}=0.05)$ to age, agriculture knowledge or age. The results from the data collected showed that $50 \%$ of the respondents thought meat products with "antibiotic-free" and "hormone-free" labels were healthier than other products not labeled. Sixty-three percent believed that meat products lacking labels contained antibiotics or hormones; however, a majority of the respondents were not concerned about purchasing meat products that were not labeled.
\end{abstract}

Keywords: Antibiotic-free, Food safety, Hormone-free, Meat labels

\title{
1. Introduction
}

Livestock production has changed drastically over the years, due to population growth, urbanization and income increases. The number of small farms has decreased, causing an increase in larger, specialized operations. With this shift in livestock production, management techniques have changed to keep up with the demand for consumable meat products. Livestock operations manage their animals efficiently, while ensuring their products raised are safe for consumers. Biotechnologies have been developed to improve livestock production practices, including the use of antibiotics and hormones.

A large portion of the American diet is dedicated to meat products. Chicken and beef are the consumed in the highest quantities, and demand is estimated to rise (National Chicken Council, 2019). By 2027, the per capita consumption of beef, pork and poultry is projected to increase from 218 pounds per person to 222 pounds (USDA, 2018). This increase in demand for available meat products requires farmers to efficiently and effectively manage livestock for meat production. The topic of hormone and antibiotic residues in meat has become controversial in recent years. Consumers are seeing an increase in meat labeled "hormone-free" and "antibiotic-free". The use of these labels as a marketing strategy is causing confusion for the consumer, raising questions about the safety of meat.

The Food Safety and Inspection Service (FSIS) is an agency within the U.S. Department of Agriculture (USDA) that ensures the safety of the county's poultry, egg and meat products, 
and uses guidelines from the U.S. Food and Drug Administration (FDA) to guarantee products available for human consumption are free of illegal residues (USDA, 2019). Meat is randomly tested for illegal residue levels after the animal is slaughtered. According to the law to ensure safety, no meat intended for human consumption is allowed to contain residues above the maximum residue level (MRL) which is set by the FDA (Beef, 2019). Inspection ensures that products available for consumers are safe, and will cause no harm to the public when consumed.

\section{Literature Review}

\subsection{Antibiotic Use}

Biotechnology helps to keep up with the demand for food in growing countries, and these practices make some consumers nervous. Serious diseases are prevented or controlled by the use of antibiotics. However, consumers associate antibiotics with chemicals, and they assume a negative connotation, thinking chemicals used in meat production are harmful to humans (Langston, 2010). Antibiotics are drugs used in certain livestock practices to maintain healthy animals by killing or preventing the growth of bacteria (USDA, 2019). The United States has allowed farmers to utilize antibiotics in animal feed for livestock production since 1989 (Liaukonyte et al., 2013). When an antibiotic is administered, the animal must go through a required FDA-approved withdrawal period before the animal can be slaughtered (USDA, 2019). The withdrawal period allows the antibiotic to be processed through the body until the drug has decreased to a safe level within the animal's tissue. This production practice ensures that meat is safe for human consumption (USDA, 2019).

Antibiotics used in animal production increase growth of the animal, which decreases production cost for the producer and results in lower meat prices for the consumer (Drovers, 2019). If antibiotic use is banned, this will drive the cost of meat higher because production will be less efficient. Although antibiotics are regulated and eliminated from the animal's body before slaughter, to ensure no health risk to humans, consumer concern relates to antibiotics used in animal production that humans use as well. Some people are concerned that use of the same antibiotics will create antibiotic resistance in bacteria that infect humans. Most scientists believe that the likelihood of antibiotic residues causing health issues is small. However, the Centers for Disease Control and Prevention reported that drugs important to human health are no longer permitted to be used in animal production (CDC, 2018). Lusk et al. (2006) studied the consumer request to ban antibiotics in pork production. The direct and indirect benefits of banning antibiotics were estimated, and the scientists conducted surveys with 442 consumers at a grocery store. Consumers preferred antibiotic-free meat and were willing to pay a higher premium; however, the results do not justify establishing a ban of antibiotic use (Lusk et al., 2006). Evidence of consumer understanding of antibiotic use in pork production practices is small. Enacting a ban on antibiotic use is not likely to change the level of demand for pork, but will increase pork prices through increased production costs. The increase in pork prices will cause demand to drop (Lusk et al., 2006). Because the current premium for antibiotic-free meat is high, establishing a ban would remove regular pork products from the market. Lusk et al. (2006) states that antibiotic use may cause a threat 
to human health, but this is not definite. Nonetheless, a ban would decrease the opportunity for antibiotic resistance to develop. The findings from this article did not justify a ban on antibiotics in animal production, but opened the door to investigate further.

Cervantes (2015) looked at antibiotic use in poultry production and noted that scientific evidence is lacking to support the claims that antibiotic use in animal production for meat causes antibiotic resistance in bacteria that infect humans. Excessive antibiotic use in humans is the likely cause of antibiotic resistance (Cervantes, 2015). Agencies designed to monitor food safety often sample and test meat products for drug residues to ensure that all products on the market do not contain residues above the maximum residue limit. Consumers believe that organic products are safer and healthier, although scientists believe the popularity of organic food products is caused by fear and misleading information. If antibiotics were removed from poultry production practices, the health of the flocks would be at risk, and the control and prevention of diseases would be costly and challenging (Cervantes, 2015). Flocks raised with alternatives to antibiotics is feasible, but this would increase producer costs and affect the flock's health and welfare. Without antibiotic use, performance and efficiency decreases, and feed and water intake per pound of meat produced increases, which causes production cost to increase and increases cost for the consumer (Cervantes, 2015).

Maintaining the health of animals in livestock production is important, while also being mindful of the consumer's health risk. Some assume that using antibiotics in livestock production for human consumption causes health risk; however, that has not been proven due to the lack of research. Contaminated meat can be hazardous if consumed, which is why government agencies have established rules and regulations to ensure that meat products do not contain unhealthy levels of antibiotic residues.

\subsection{Hormone Use}

With the growing population, production agriculture needs to be as efficient as possible to meet the demand for food. The term "hormone-free" meat is a false statement, because all plants and animals naturally produce hormones. Hormones are required for an animal to survive. Producers use added hormones to increase growth and feed efficiency to keep up with the high demand for meat products.

In relation to hormones in food production, Ghandi and Snedeker (2000) wrote a fact sheet addressing consumer concerns about hormones in food production. The Food and Drug Administration (FDA) has approved six hormones for use in livestock production. Estradiol, progesterone and testosterone are natural sex hormones (Ghandi \& Snedeker, 2000). Because these hormones are produced naturally by animals, monitoring for these residues in meat is not possible. Melengesterol acetate, trenbolone acetate and zeranol are synthetic hormones that promote growth (Ghandi \& Snedeker, 2000). Tolerance levels of these hormones are regulated when inspecting meat for human consumption. These six hormones are used in cattle and sheep production. Hormones are not administered to animals in the pork or poultry industries (USDA, 2011). The fact sheet confirmed that no research-based information suggests that consuming meat from animals that were given added hormones during production increases health risks in humans, including breast cancer or early onset of puberty. 


\section{Ml Macrothink}

However, Ghandi and Snedeker (2000) suggested that a large-scale study be performed to compare the health of people who consume hormone-treated meat to the health of those that eat meat from only untreated animals.

Raloff (2002) discussed how hormone use in cattle poses risks to humans not in meat residues, but through the environment. Hormones that are not absorbed by the animal's body are excreted, and end up in nearby water sources that eventually become drinking water for humans. Raloff (2002) included information from research teams led by L.J. Guillette and A.M. Soto who reported about the danger of excreted livestock hormones. Hormones were found in water sites downstream from feedlots in Nebraska due to runoff; these hormones caused adverse effects to minnows (Raloff, 2002). Hormones found in stored manure resisted breakdown by bacteria. When applied as liquid fertilizer to fields, hormone residue lasted a little over one week but hormones in dried manure fertilizer lasted about two months (Raloff 2002). However, the disappearance of hormone residue in the liquid fertilizer could be caused by runoff. The issue presented within this article focuses on the potential contamination of drinking water from hormones excreted from animals and the risk those hormones pose to humans instead of humans consuming hormones in meat. The FDA has contradicted this claim. FDA stated that natural hormones and synthetic hormones used in beef does not create a significant risk to environmental quality (Drovers, 2012).

Lusk et al. (2003) surveyed consumers to find if a difference existed in consumer preference for beef that had been administered added hormones or fed genetically modified (GM) corn during production compared to beef not fed GM corn or free from added hormones. A survey was mailed to 1000 participants in Germany, 2500 in the United States, 1000 in France and 1000 in the United Kingdom. In the survey, consumers could choose between quality variables of ribeye steaks with different amounts of marbling, tenderness, and price. Also, the consumers could choose between beef that was treated with growth hormones or fed genetically modified corn during production. This choice experiment allowed the consumer to pick the factors important to them when making their beef selection. Two modeling approaches were used in this study to accommodate the variation among countries surveyed. Consumers from the United States had less concern about using genetic engineering and the use of growth hormones in animal production than those from European countries. Also, European consumers are willing to pay more for beef that was not given hormones or genetically modified corn compared to American consumers. French consumers valued beef that had not been given growth hormones more than consumers from the United States and were willing to pay more for that beef. Consumers from the United Kingdom, United States and Germany had no recognizable difference in the value placed on beef that was not treated with hormones. European consumers reported they were willing to pay more for beef that had not been fed genetically modified corn in comparison to consumers from the United States.

As stated previously, hormone use in meat productions is a management practice that does not negatively affect the consumer. Without utilizing added hormones, production efficiency would be impacted, which would result in less availability of meat products, and higher costs. Meat products are inspected to ensure residue levels do not exceed an unhealthy amount, to maintain quality food safety standards. 


\subsection{Product Labeling}

Recently the demand for transparency of food ingredients has increased. Consumers rely on food labels to help them assess what they are ingesting. Labels are helpful, but can also cause confusion for the consumer. Many studies have found that food labels have a large impact on demand, and influence consumers' purchases (Liaukonyte et al., 2013; Yang et al., 2017)

Liaukonyte et al. (2013) examined the effects that labels, and primary and secondary information have on consumers' perception and willingness to pay for certain food products. Labels that display primary information include "contains X" or "free of X". Secondary information is the explanation of ingredients or the processes that were used to raise the products. Consumer behavior changes depending on the presence of negative label information, ("contains X"), compared to positive labeling ("free of X"). A sample of 351 adults were given $\$ 25$, which could be used to bid on food items shown in auctions during the study, but they also had the option to not purchase the items. The food items included: beef jerky, chewy granola bar, granola trail mix, gummy bears, mozzarella string cheese, oven-baked potato chips, and soft-baked oatmeal chocolate chip cookies. During the auction of each item, descriptions of the products were shown to the participants, which included food ingredients and food processes used during production. Study subjects were presented with products that included a variety of pairings of label information including "contains X" with positive or negative secondary information about $\mathrm{X}$, "free of $\mathrm{X}$ " with positive or negative secondary information about X, "contains X" with no secondary information about $\mathrm{X}$ and "free of $\mathrm{X}$ " with no secondary information. Consumers had a negative reaction for the label "contains X" and were willing to pay less for products with that label due to the lack of secondary information. The "free of X" label with negative secondary information was the only treatment that was statistically significant to positively change the consumer's willingness to pay. "Free of X" label with no statement of what the product was free from did not influence willingness to pay. Liaunkonyte et al. (2013) conclude that labels directly influence willingness to pay and consumers prefer products listed as "free of negative ingredients". Consumers were negatively impacted by all labels that included "contains X", however, the "contains X" label with no additional information had the greatest negative impact on the consumers' willingness to pay for those products. The results prove that labels lacking supplemental information affects consumer understanding, which has the potential to mislead their choices.

Yang et al. (2017), studied the potential effects that hormone use in meat products have on consumer perception, and consumer willingness to pay for meat products not administered added hormones during production. Survey participants were asked to make nine choices among eight types of food products: bean, chicken breast, chicken wings, ham, hamburger, pasta, pork chop, steak and a "no purchase" option. Participants were also asked for amounts they were willing to pay for products with "no added hormone" labels. Standard t-tests were performed to determine the consumer views of hormones used in pork, chicken and cattle production, in comparison with the prevalence of actual hormone use in those areas of production. Consumers assume higher use of hormones in the poultry and pork industries, and lower use of hormones in the beef industry, compared to actual hormone use (Yang et al., 


\section{Macrothink}

2017). Consumers lack knowledge of livestock production industries, and assume hormones are used in poultry and hogs, when hormones are not legally allowed in poultry and pork production. Perceived hormone use did affect the demand for meat products, and consumers were willing to pay more for meat with labels stating that hormones were not added during production. This study showed that because consumers are not properly informed about livestock production for meat products, they are negatively influenced by meat product labels.

With the growing concern of meat traceability, the use of food labels can potentially be a helpful resource for consumers when purchasing products. The downfall to product labels is the confusion they cause for consumers. Because most consumers do not understand agricultural practices, food labels can create a negative connotation towards agriculture. This is unfortunate because consumers are often misled when purchasing products, which can hurt the agriculture industry.

\section{Objectives}

The purpose of this study was to assess consumer perception of meat labeled antibiotic-free and hormone-free. The following objectives were determined:

1) Identify the concern about purchasing meat products not labeled hormone or antibiotic free

2) Determine consumers view of hormone and antibiotic free meat being healthier than meat not labeled

3) Increase the awareness of consumer safety when purchasing meat products not labeled antibiotic-free and hormone-free

\section{Data and Methods}

\subsection{Instrument Design}

A fifteen-question survey was developed to address the objectives of this study. Survey questions were created to determine consumer perception of meat labeled antibiotic-free and hormone-free. Qualitative and quantitative survey questions were used, and the survey was administered via an email link to Qualtrics.com. The protocol for the survey was reviewed and approved by the University of Tennessee at Martin Institutional Review Board Committee (2019-747-E05-4005/Whit,Lin).

\subsection{Survey Procedures}

The email lists for the survey consisted of high school faculty and staff at two schools in Coffee County, Tennessee. The survey link was emailed to approximately 162 participants. The email stated that the fifteen-question survey would take no more than ten minutes to complete, it was voluntary, responses were confidential, and participants could withdraw at any time. Participants electronically consented to partake by clicking the survey link. The survey was emailed to all participants on April 15, 2019 requesting participation and it was closed on April 29, 2019. A total of 91 respondents completed the survey for a participation 


\section{Macrothink}

rate of $56 \%$. Qualtrics was used to collect the data for this study.

\subsection{Statistical Analysis}

Microsoft Excel was used to analyze the survey results. Chi-square tests were used to determine if age, agriculture knowledge or education level was related to the participants' responses to selected survey questions.

\section{Results and Discussion}

Out of the 91 respondents of the survey, $26.37 \%$ were male and the majority $(73.63 \%)$ were female (Table 1). The education of participants varied between levels, with the highest education groups being $37.36 \%$ for master's degree and $31.87 \%$ for bachelor's degree (Table 1). The ages of participants ranged from 20 years to 65 years and over. The majority $(21.98 \%)$ age category was 41-45 years of age (Figure 1). When asked to describe their knowledge of agriculture, $27.47 \%$ chose below average, the majority (57.14\%) chose average, and $15.38 \%$ chose above average (Figure 2).

Table 1. Socio-Demographics of survey respondents

\begin{tabular}{lllc}
\hline Characteristic & & Percentage (\%) & Respondents \\
\hline \multirow{2}{*}{ Gender } & Male & 26.37 & 24 \\
Highest level of education & Female & 73.63 & 67 \\
& High school/GED & 9.89 & 9 \\
& Associates Degree & 6.59 & 6 \\
& Bachelor's Degree & 31.87 & 29 \\
& Master's Degree & 37.36 & 34 \\
& Professional Degree & 7.69 & 7 \\
& Doctoral Degree & 1.10 & 1 \\
& Other & 5.49 & 5 \\
\hline
\end{tabular}




\section{Macrothink}

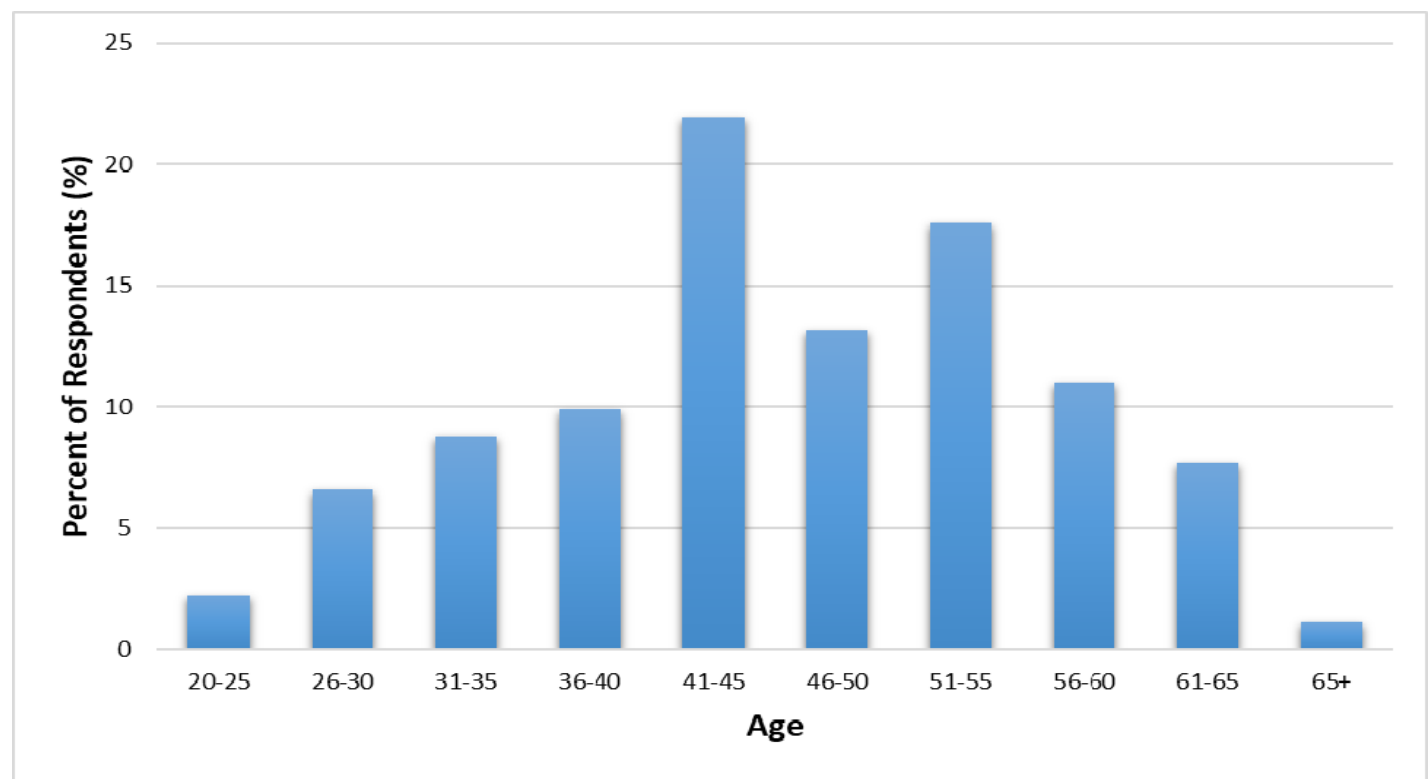

Figure 1. Age groups of survey respondents

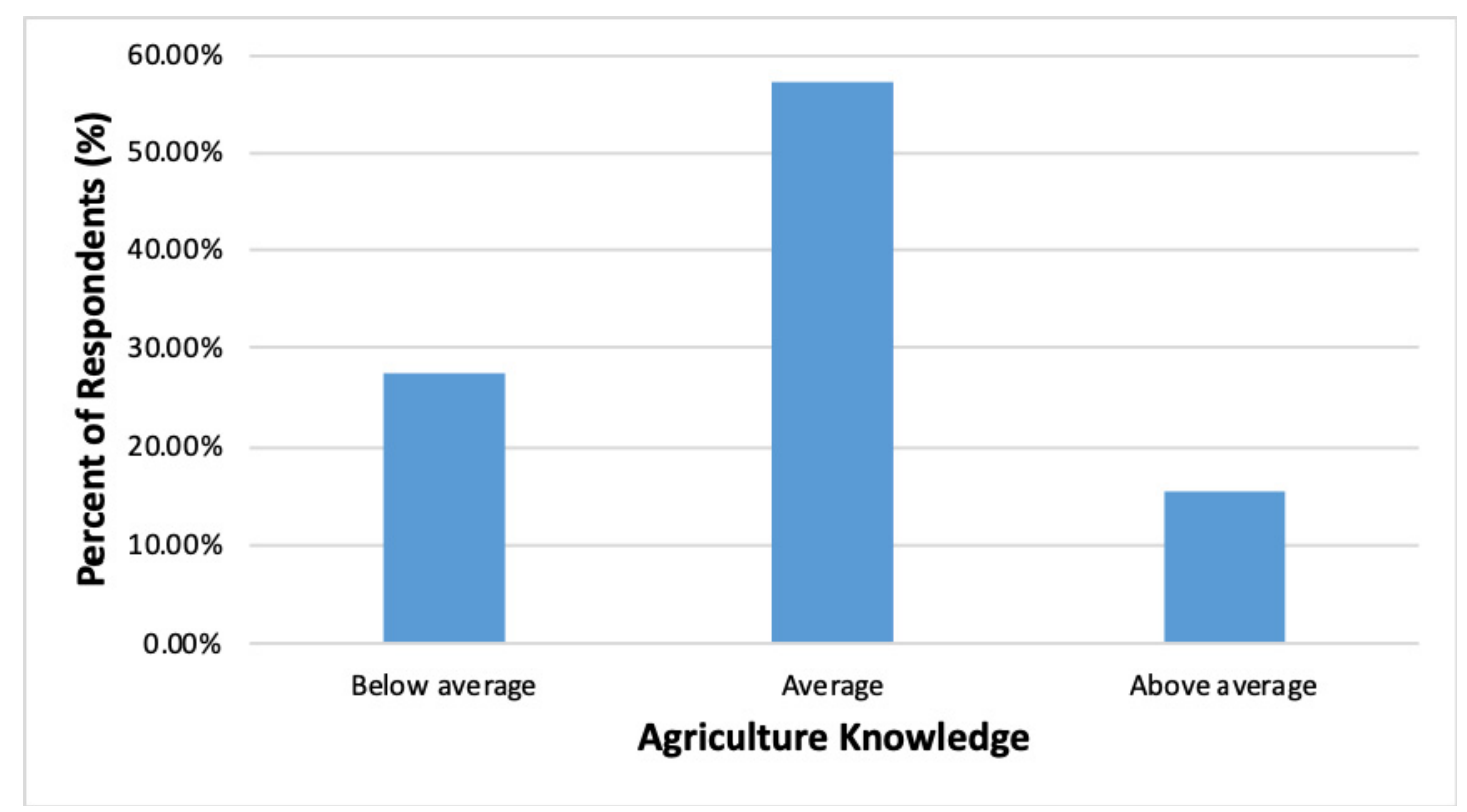

Figure 2. Survey respondents' description of their agriculture knowledge

All of the respondents consumed meat products. The type of meat consumed varied, but beef (46.15\%) and poultry (45.05\%) were the most preferred over fish, pork, lamb and other types (Figure 3). Meat was consumed at least once per week by respondents, with a majority $(48.35 \%)$ eating meat six or seven days per week (Table 2). Eighty-nine percent of consumers surveyed purchase meat products from the grocery store (Figure 4), with a majority $(43.96 \%)$ traveling five to ten miles to buy the products (Figure 5). Multiple grocery stores exist in the area of the respondents, which explains the results of low travel distance. Only 45 participants responded to the question asking why they choose to not consume meat products 


\section{Macrothink}

(Table 3). Some of the respondents explained that they skipped this question because they do consume meat and none of the reasons inhibited their choice to eat meat products.

According to the results from the Chi-square tests, there was no significant relationships between education level and the responses to the survey questions (Table 4). Consumer perception of labeled meat being healthier than non-labeled products, concern for non-labeled products, willingness to pay more for labeled products, and perception of non-labeled meat containing hormones or antibiotics was also not related to consumer age. (Table 4). Agriculture knowledge affected consumers' concern for purchasing meat not labeled $(\mathrm{P}=0.0362)$, perception of labeled meat being healthier $(\mathrm{P}=0.0017)$, and their willingness to pay more for labeled meat products $(\mathrm{P}=0.0009$; Table 4$)$. While $50 \%$ of the respondents think that antibiotic-free and hormone-free labeled meat is healthier (Figure 6), 56.04\% replied they would not pay more for those products (Table 5).

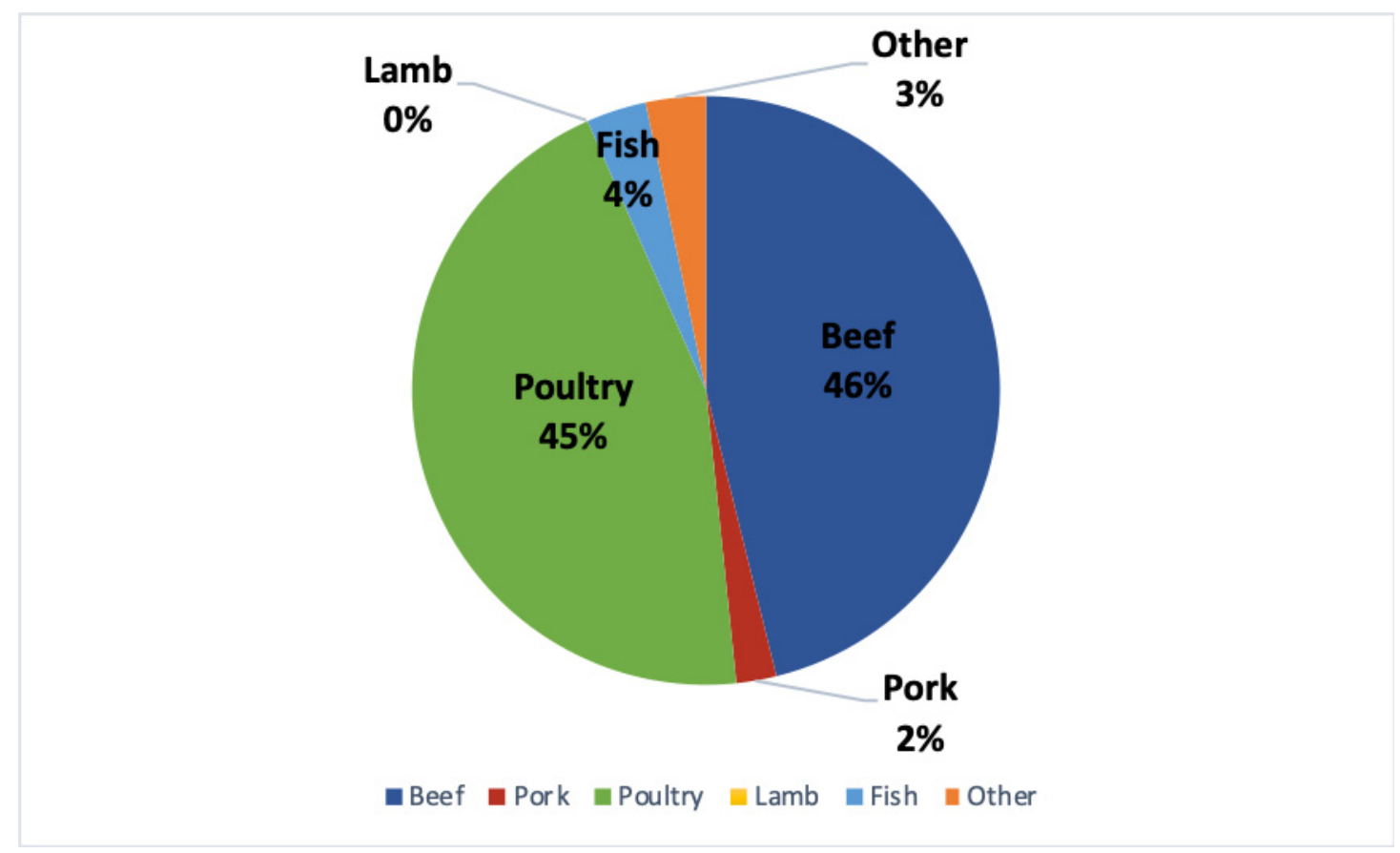

Figure 3. Types of meat primarily consumed by respondents of the survey 


\section{Macrothink}

Table 2. Frequency of meat consumed by respondents of the survey.

\begin{tabular}{lll}
\hline Days per week & Percentage $(\%)$ & Respondents \\
\hline Less than 1 & 0 & 0 \\
1 & 2.2 & 2 \\
$2-3$ & 28.57 & 26 \\
$4-5$ & 20.88 & 19 \\
$6-7$ & 48.35 & 44 \\
\hline
\end{tabular}

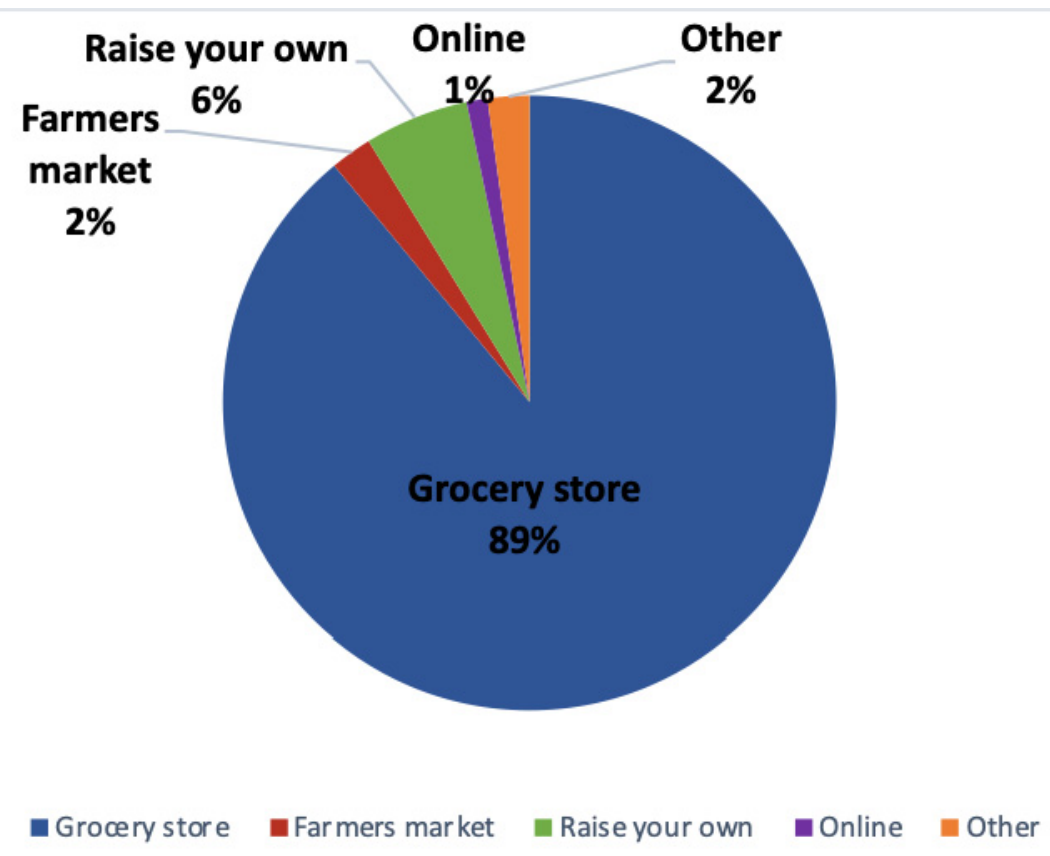

Figure 4. Location of where survey respondents purchase meat products 


\section{Macrothink}

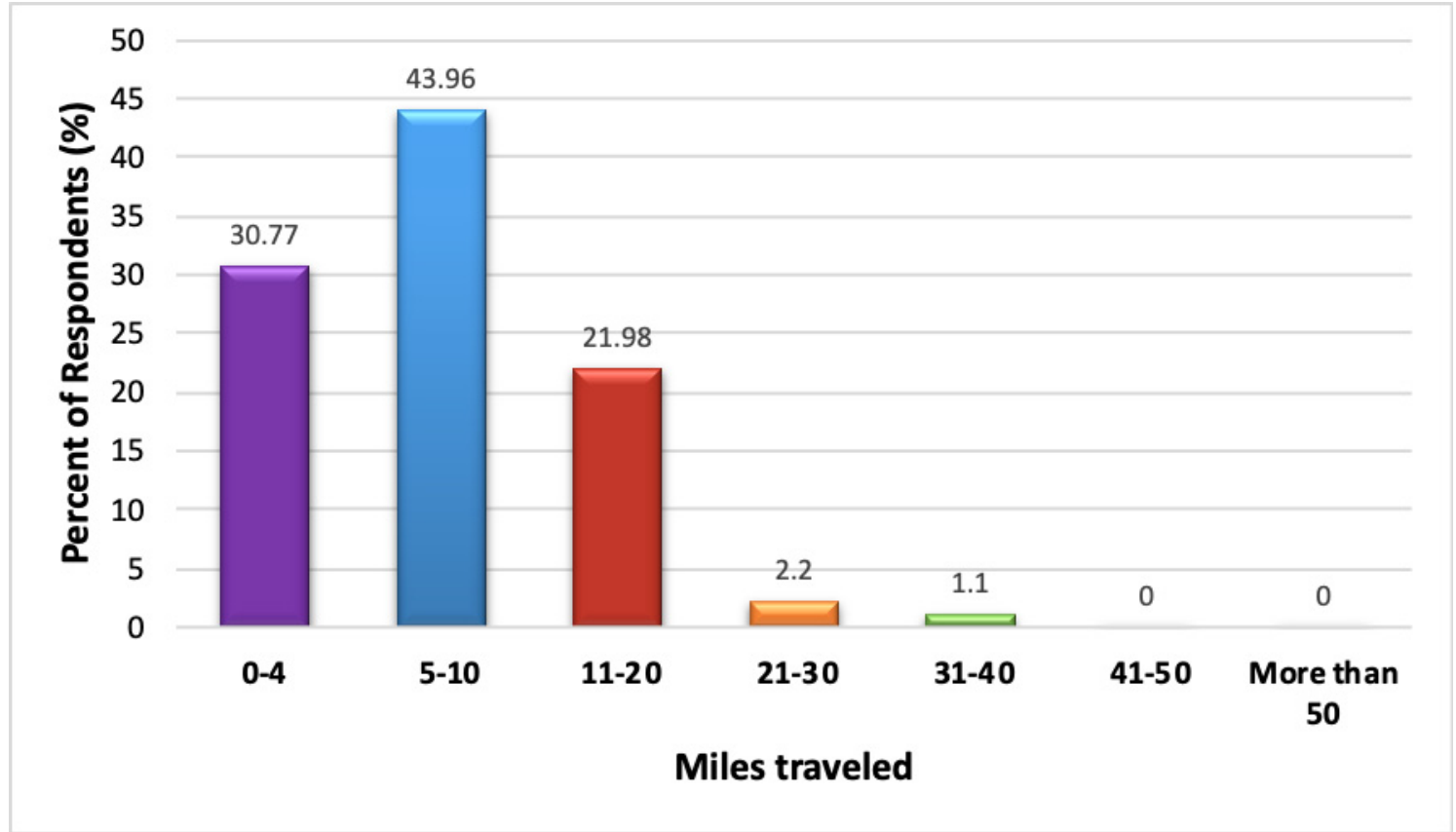

Figure 5. Miles survey respondents generally travel to purchase meat products

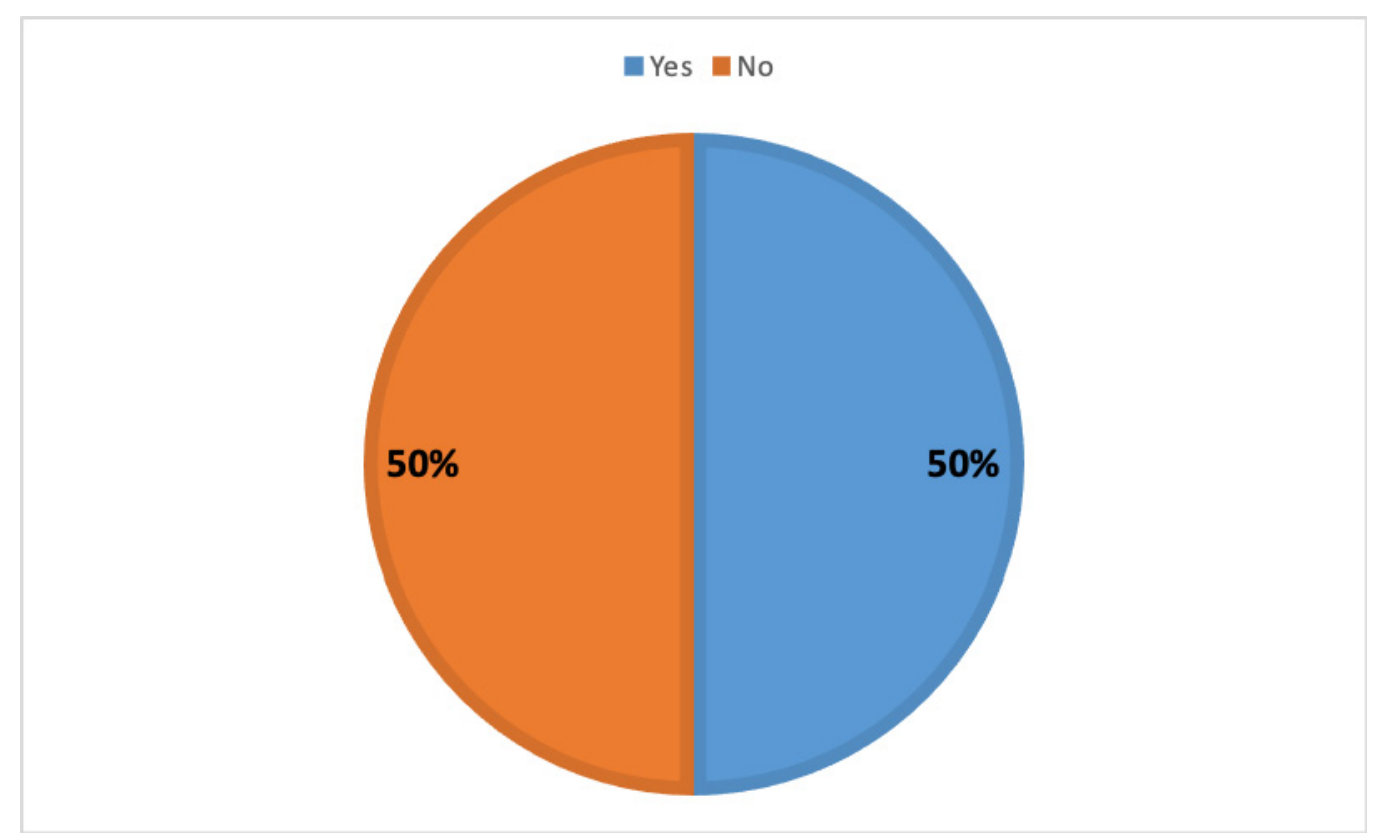

Figure 6. Survey respondents' perception of labeled meat products being healthier than other products not labeled 


\section{1) Macrothink}

Table 3. Reasons survey respondents choose to not consume meat products

\begin{tabular}{lll}
\hline Reasons & Percentage (\%) & Respondents \\
\hline Unpalatable & 6.67 & 3 \\
Health Issues & 17.78 & 8 \\
Concerns of how products are raised & 11.11 & 5 \\
Religious reasons & 0 & 0 \\
Too expensive & 26.57 & 12 \\
Other & 37.78 & 17 \\
\hline
\end{tabular}

Table 4. Results of data analysis to identify relationship among age, agriculture knowledge, education, concern for meat not labeled, perception of labeled meat being healthier, and idea of non-labeled meat containing hormones and/or antibiotics

\begin{tabular}{|c|c|c|c|}
\hline \multirow[b]{2}{*}{ Perception of Consumers } & \multicolumn{3}{|l|}{ P-Value } \\
\hline & $\begin{array}{l}\text { Agriculture } \\
\text { Knowledge }\end{array}$ & $\begin{array}{l}\text { Education } \\
\text { Level }\end{array}$ & Age \\
\hline Concern for purchasing meat not labeled & $0.0362 *$ & 0.1772 & 0.5117 \\
\hline Perception of labeled meat being healthier & $0.0017 *$ & 0.6043 & 0.2356 \\
\hline Idea of non-labeled meat containing hormones/antibiotics & 0.2235 & 0.4920 & 0.3946 \\
\hline Willingness to pay more for labeled meat products & $0.0009 *$ & 0.6741 & 0.8885 \\
\hline
\end{tabular}

* P-values are significant with an $\boldsymbol{\alpha}$ of 0.05 .

Table 5. Survey respondents' willingness to pay more for meat products labeled antibiotic-free and hormone-free and if respondents have purchased antibiotic-free or hormone-free meat purchases over the past 12 months

\begin{tabular}{lll}
\hline & Percentage (\%) & Respondents \\
\hline Willingness to pay more & & \\
Yes & 43.96 & 40 \\
No & 56.04 & 51 \\
Purchased antibiotic- or hormone-free products & & \\
Yes & 63.74 & 58 \\
No & 36.26 & 33 \\
\hline
\end{tabular}

\section{Conclusion}

Conclusions can be drawn that labels have an impact on the way consumers purchase products. Because food safety is an issue globally, proper guidelines are followed to make sure that livestock raised for meat consumption produce healthy food options with no risk to humans. Hormones and antibiotics aid in the efficiency and effectiveness of animal 
production to maintain health for the animals while keeping up with demand from consumers. Residue levels in meat are monitored by government agencies to ensure all products are safe for the consumer. If hormones or antibiotics are not properly administered and managed by the producer, meat inspection agencies will penalize those involved and discard the products if residues above the appropriate limit are found. The levels of antibiotics and hormones allowed in meat are not harmful to human health. While labels are beneficial in informing the consumer of certain production practices that were use, they can create confusion or fear of other products that are just as safe, but not labeled antibiotic-free or hormone-free. The importance of educating the consumer and making them aware that hormone and antibiotic use is needed but also safe to humans is essential.

\section{References}

Centers for Disease Control and Prevention (CDC). (2018). Antibiotic/Antimicrobial Resistance (AR/AMR). September 10, 2018.

Cervantes, H. M. (2015). Antibiotic-free poultry production: is it sustainable? Journal of Applied Poultry Research, 24, 91-97. https://doi.org/10.3382/japr/pfv006

Drovers. (2012). The facts about hormones and beef. September 10, 2012.https://www.drovers.com/article/facts-about-hormones-and-beef

(Accessed 10 June 2019).

Gandhi, R,. \& Snedeker, S. M. (2000). Consumer concerns about hormones in food. Cornell University Program on Breast Cancer and Environmental Risk Factors in New York State (BCERF). $\quad$ Fact $\quad$ Sheet $\quad$ No. 37. https://ecommons.cornell.edu/bitstream/handle/1813/14514/fs37.hormones.pdf (Accessed 10 June 2019).

Langston, N. (2010). Modern Meat: Hormones in Livestock. In Toxic Bodies: Hormone Disruptors and the Legacy of DES. Yale University Press. New Haven, London.

Liaukonyte, J., Streletskaya, N. A., Kaiser, H. M., \& Rickard, B. J. (2013). Consumer response to "contains" and "free of" labeling: evidence from lab experiments. Applied Economic Perspectives and Policy, 35(3), 476-507. https://doi.org/10.1093/aepp/ppt015

Lusk, J. L., Norwood, F. B., \& Pruitt, J. R. (2006). Consumer demand for a ban on antibiotic drug use in pork production. American Journal of Agricultural Economics, 88(4), 1015-1033. https://doi.org/10.1111/j.1467-8276.2006.00913.x

Lusk, J. L., Roosen, J., \& Fox, J. A. (2003). Demand for beef from cattle administered growth hormones or fed genetically modified corn: a comparison of consumers in France, Germany, the United Kingdom, and the United States. American Journal of Agricultural Economics, 85, 16-29. https://doi.org/10.1111/1467-8276.00100

National Chicken Council. (2019). Per capita consumption of poultry and livestock, 1965 to estimated 2019, in pounds. https://www.nationalchickencouncil.org/about-the-industry/statistics/per-capita-consumptionof-poultry-and-livestock-1965-to-estimated-2012-in-pounds/ (Accessed 16 June 2019).

Raloff, J. (2002). Hormones: here's the beef. Science News, 161(1), 10-12. https://doi.org/10.2307/3977733 


\section{Macrothink}

Journal of Food Studies

ISSN 2166-1073 2020, Vol. 9, No. 1

United States Department of Agriculture (USDA). (2011). Meat and Poultry Labeling Terms. https:/www.fsis.usda.gov/wps/wcm/connect/e2853601-3edb-45d3-90dc-1bef17b7f277/Meat _and_Poultry_Labeling_Terms.pdf?MOD=AJPERES (Accessed 1 June 2019).

United States Department of Agriculture (USDA). (2018). USDA Agricultural Projections to 2027. https://www.ers.usda.gov/webdocs/publications/87459/oce-2018-1.pdf?v=0 (Accessed 16 June 2019).

United States Department of Agriculture (USDA). (2019). The Food Safety and Inspection Service Questions and

Answers. https://www.fsis.usda.gov/wps/wcm/connect/22dd2ec9-2e85-46f8-8d81-32456616fbbf/Qand A2018.pdf?MOD=AJPERES (Accessed 1 June 2019).

Yang, R., Raper, K. C., \& Lusk, J. L. (2017). February. The impact of hormone use perception on consumer meat preference. Paper presented at the annual meeting of Southern Agricultural Economics Association, Mobile, AL.

\section{Copyright Disclaimer}

Copyright for this article is retained by the author(s), with first publication rights granted to the journal.

This is an open-access article distributed under the terms and conditions of the Creative Commons Attribution license (http://creativecommons.org/licenses/by/4.0/). 